were "failures" and more than one-third actually regained all the weight lost. Moreover, though most of the "successes" or "modified successes" continued to maintain a steady weight the incidence of failure increased with the length of followup. This was especially true during the first 12 months, and follow-up reports for such short periods are of limited value. The results for the male and female patients appeared to be similar and suggest that those most overweight are least likely to succeed; however, the initial percentage excess weight was of no clear predictive value. We failed to substantiate the previous impression that the ability to reduce to within $25 \%$ in excess of the ideal weight is associated with increased prospeots of long-term success. Long-term success, however, is closely correlated with regular attendance at the follow-up clinic, and only two patients were known to have kept their weight down despite a lengthy lapse of follow-up. Some of the patients who regained weight rapidly admitted that though superficially their eating habits had been reformed they continued to eat excessively but in secret.

All the patients were "failures" before admission and the primary reason for selection was their inability to respond satisfactorily to conventional treatment despite regular supervision at an obesity clinic for at least a year. All were suffering either physically or psychologically from their morbid obesity. Thus for the small proportion of successes a mean weight loss of $27 \mathrm{~kg}$ at a mean follow-up of 27 months represents a wonthwhile achievement. Success, however, cannot be gauged solely in terms of weight reduction. Ten patients had 12 elective operations, including hiatus hernia repair, cholecystectomy, and total hip replacement. Nine married, and among the women there were six pregnancies, including one full-term delivery in a previous habitual abonter. Eleven patients held jobs which previously they could not have obtained. It follows that the distinction between success and failure is necessarily arbitrary, and many who regained weight did not regret the time spent in hospital.

Therapeutic starvation could be better justified if patient selection were improved, but at present the long-term sequelae of the other form of radical therapy, bypass surgery, are uncentain. The current policy is to offer surgery only to selected patients who have regained weight after starvation.

We wish to thank the many doctors, the nursing staff, and the other staff who were concerned in the care of these patients, and are grateful to Servier Laboratories for their very generous financial support.

\section{References}

Bloom, W. L. (1959). Metabolism, 8, 214.

Gilliland, I. C. (1968). Postgraduate Medical fournal, 44, 58.

Harrison, M. T., and Harden, R. M. (1966). Lancet, $2,1340$.

Harrison, M. T., and Harden, R. M. (1966). Lancet, 2, 13.

Hermann, L. (1966). Fournal of the American Medical Association, 197, 22

Kollar, E. J., Atkinson, R. M., and Albin, D. L. (1968). Psychosomatics, 10, 125.

Maague, H., and Mogensen, E. F. (1970). Danish Medical Bulletin, 17, 206.

MacCuish, A. C., Munro, J. F., and Duncan, L. J. P. (1968). British Medical Fournal, 1,91 .

Munro, J. F., MacCuish, A. C., Goodall, J. A. D., Fraser, J., and Duncan, L. J. P. (1970). British Medical fournal, 4, 712.

Rooth, G., and Carlström, S. (1970). Acta Medica Scandinavica, 187, 455 Swanson, D. W., and Dinello, K. (1970). Psychosomatic Medicine, 32, 209.

\title{
Secondary Respiratory Infection in Hospital Patients: Effect of Antimicrobial Agents and Environment
}

\author{
J. R. PHILP, R. C. SPENCER
}

British Medical fournal, 1974, 2, 359-362

\section{Summary}

A prospective study of 358 medical and 234 postoperative patients with clinical evidence of secondary chest infection showed that previous administration of antimicrobial agents greatly reduced the chance of obtaining a clear-cut laboratory report. In patients with radiographical evidence of pneumonia this led to a fourfold decrease in the overall rate of isolation of potential pathogens. Furthermore, 81 diverse "coliforms" were isolated from 258 medical and surgical patients who had received previous antimicrobial therapy while only four coliforms (all Escherichia coli) were isolated from 334 untreated patients. Thus the general hospital environment on its own seemed to have a negligible influence

\footnotetext{
Department of Bacteriology, Wright-Fleming Institute, St. Mary's Hospital, London W.2

J. R. PHILP, M.D., M.R.C.P., Associate Professor of Medicine (Present address: Department of Medicine, Bowman Gray School of Medicine, Winston-Salem, North Carolina 27103)

R. C. SPENCER, M.B., B.S., Senior Registrar
}

in promoting the growth of coliform flora in sputum. Any unique effect of underlying disease in this regard was masked by that of previous therapy. Finally, the results raised the possibility that previous antimicrobial therapy might have increased the risk of secondary pneumonia in hospital patients.

\section{Introduction}

In the six months before this study a pilot study showed that potential bacterial pathogens were isolated from less than a third of 1,560 sputa investigated in this laboratory. Of these isolates $56 \%$ were Gram-negative "coliform" bacilli whose significance was often difficult to assess. Consequently this study was carried out in an attempt to correlate bacterological findings in sputum with radiographical appearances, underlying disease (Stratford et. al., 1968; Johansen et. al., 1969), residence in the hospital environment (Johansen et al., 1972), and previous administration of antimicrobial agents (Lipman et al., 1946; Ory et al., 1946; Long, 1947; Meads et al., 1951; McCurdy and Neter, 1952; Elmes et al., 1953; Petersdorf et al., 1957; Louria and Kaminski, 1962; Tillotson and Finland, 1969; Price and Sleigh, 1970). It was hoped to define more clearly the clinical significance of various potential pathogens with a view to more rational therapy in individual patients. 


\section{Patients and Methods}

The population studied consisted of consecutive adult patients from whom a sputum sample had been sent to the laboratory because they had developed clinical evidence of secondary chest infection after admission to hospital. Patients admitted with a primary diagnosis of pneumonia and those with a history of chronic lung disease-for example, asthma, bronchiectasis, chronic bronchitis, or emphysema-were excluded. Of the 592 patients studied 234 were postoperative surgical patients and 358 were medical patients in whom chest infection was secondary to other disease.

Each specimen of sputum was inspected and a Gram-stained film examined. Clear specimens which contained only oral epithelial cells and no pus cells were regarded as salivary in origin and were excluded from the study. Whenever possible a purulent portion of sputum was seleoted for inoculation on to blood agar, MacConkey agar, and heated blood-agar plates. These were read after overnight incubation and potential pathogens were identified by standard methods (Cowan and Steel, 1965). Arbitrarily, we did not regand a few colonies of potential pathogens found only in the inoculation well as significant. The laboratory information was correlated with the patient's clinical category (medical or surgical), pretreatment with antimicrobial agents, and a radiologist's report of the chest radiograph.

\section{Results}

The results showed that in both medical and surgical groups previous antimicrobial therapy was the outstanding factor influencing both the rate and pattern of isolation of potential bacterial pathogens (see table). In those patients with radiographical evidence of pneumonia Streptococcus pneumoniae was never isolated, and Haemophilus influenzae was isolated on only one occasion from 25 medical and 42 surgical patients who had received previous therapy. In contrast, Str. pneumoniae was isolated 22 times (54\%) and $H$. influenzae 11 times (27\%) from 17 medical and 24 surgical patients with radiographical consolidation, who had not already been treated. Thus in untreated patients with secondary pneumonia Str. pneumoniae and $H$. influenzae were by far the commonest potential pathogens isolated from sputum.

In medical patients with pneumonic consolidation previous therapy increased the proportion of patients from whom no potential bacterial pathogens were isolated threefold-from $12 \%$ to $32 \%$. The corresponding increase for surgical patients was fivefold-from $8 \%$ to $43 \%$. It is of additional interest that in both medical and surgical patients without pneumonic consolidation the difference between treated and untreated groups was minimal by comparison (see table).

The effect of previous therapy on the growth of coliforms in sputum was striking. Escherichia coli, but no other type of coliform, was isolated from only three of 219 untreated medical patients and from only one of 115 untreated surgical patients. In previously treated patients without radiographical evidence of pneumonia, however, diverse coliforms were found in 24 out of 114 medical patients and 20 out of 77 surgical patients. In patients with radiographical evidence of pneumonia previous therapy was associated with an even higher incidence of coliforms, which were found in the sputum of 14 out of 25 medical patients and 23 out of 42 surgical patients. Thus the clinical significance of coliforms in the sputum of an individual patient was often difficult to define, especially as these observations suggested that their presence was largely determined by previous antimicrobial therapy. This conclusion was supported by the fact that in only five of the 81 previously treated patients from whom coliforms were isolated were the organisms sensitive to agents already employed. These patterns suggested that the initial effect of antimicrobial agents may be to increase colonization of the respiratory tract with resistant coliforms. This, in combination with other undefined factors, may make infection with these organisms more likely but not inevitable.

Previous therapy had no effect on the prevalence of Staphylococcus aureus in sputum from the various groups. This organism was found in only $1 \%$ of medical patients without radiographical pneumonia whether previously treated or not. While the frequency of isolation was increased in medical patients with radiographical pneumonia again the incidence was not influenced by previous therapy (see table). In surgical patients Staph. aureus was rare or absent from sputum in all sub-categories. This might have been due to the fact that many surgical patients who were found on preoperative screening to be carriers of Staph. aureus were treated with a topical anti-staphylococcal preparation.

Finally, the results raised the possibility that previous therapy might actually have increased the absolute risk of secondary pneumonia in hospital patients. Thus in previously untreated medical patients developing a productive cough, 17 out of $219(8 \%)$ had radiological evidence of pneumonia compared with 25 out of $139(18 \%)$ in previously treated patients. For the surgical patients radiological evidence of pneumonia was present in 24 out of $115(21 \%)$ patients who had had no antimicrobial agents and in 42 of the 119 (35\%) who had received treatment. It must be emphasized, however, that the patients for this study were initially selected because they had showed evidence of secondary chest infection including a productive cough and not according to whether previous treatment had been given. Consequently, these results do not decide whether previous therapy increases the risk of developing a productive cough but they do suggest that if a patient in hospital does develop a productive cough previous therapy is associated with an increased risk of pneumonia.

\section{Discussion}

The secondary development of clinical features suggestive of respiratory infection is common in postoperative cases and in

Bacteriological and Radiographical Findings and Effect of Previous Antimicrobial Therapy in 358 Medical and 234 Surgical Patients

\begin{tabular}{|c|c|c|c|c|c|c|c|c|c|c|}
\hline & & & \multicolumn{4}{|c|}{ Medical Patients } & \multicolumn{4}{|c|}{ Surgical Patients } \\
\hline \multirow{2}{*}{\multicolumn{3}{|c|}{ Organisms Isolated }} & \multicolumn{2}{|c|}{$\begin{array}{c}\text { Consolidation on } \\
\text { Radiograph }\end{array}$} & \multicolumn{2}{|c|}{$\begin{array}{l}\text { No Consolidation on } \\
\text { Radiograph }\end{array}$} & \multicolumn{2}{|c|}{$\begin{array}{c}\text { Consolidation on } \\
\text { Radiograph }\end{array}$} & \multicolumn{2}{|c|}{$\begin{array}{l}\text { No Consolidation on } \\
\text { Radiograph }\end{array}$} \\
\hline & & & 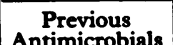 & $\begin{array}{c}\text { No Previous } \\
\text { Primicobials }\end{array}$ & $\begin{array}{c}\text { Previous } \\
\text { Antimicrobials }\end{array}$ & $\begin{array}{l}\text { No Previous } \\
\text { Antimicrobials }\end{array}$ & $\begin{array}{c}\text { Previous } \\
\text { Antimicrobials }\end{array}$ & $\begin{array}{l}\text { No Previous } \\
\text { Antimicrobials }\end{array}$ & $\begin{array}{c}\text { Previous } \\
\text { Antimicrobials }\end{array}$ & No Previous \\
\hline 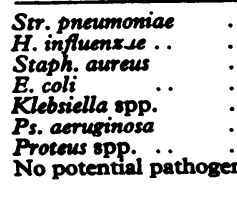 & 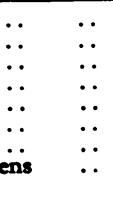 & $\begin{array}{r}\because \\
\because . \\
\because . \\
\ddot{.} \\
\text { Total }\end{array}$ & $\left.\begin{array}{l}\left.\begin{array}{l}0 \\
0\end{array}\right\}(0) \\
3(12 \%) \\
3 \\
6 \\
4 \\
1 \\
8 \\
25\end{array}\right\}(52 \%)$ & $\left.\begin{array}{l}8 \\
4 \\
2 \\
1 \\
0 \\
0 \\
0 \\
2 \\
17\end{array}\right\}(12 \%)(71 \%)$ & $\left.\begin{array}{r}0 \\
1 \\
1\end{array}\right\}(1 \%)$ & $\left.\begin{array}{r}10 \\
6\end{array}\right\}(8 \%)$ & $\left.\begin{array}{r}0 \\
1 \\
0 \\
11 \\
6 \\
5 \\
1 \\
18 \\
42\end{array}\right\}(25 \%)$ & $\left.\begin{array}{r}\left.\begin{array}{r}14 \\
7\end{array}\right\}(88 \%) \\
0(0) \\
1 \\
0 \\
0 \\
0 \\
2 \\
24\end{array}\right\}(8 \%)$ & $\left.\begin{array}{r}\left.\begin{array}{r}0 \\
1\end{array}\right\}(1 \%) \\
3 \\
10 \\
8 \\
2 \\
0 \\
53 \\
77 \\
77\end{array}\right\}(26 \%)$ & $\left.\begin{array}{r}8 \\
10 \\
0 \\
0 \\
0 \\
0 \\
0 \\
0 \\
73 \\
91\end{array}\right\}(80 \%)$ \\
\hline
\end{tabular}


patients admitted to medical wards with other diseases such as neoplasm, myocardial infarction, and strokes. Furthermore, the recent overall increase in the incidence of Gram-negative coliform infections in hospital patients has made the interpretation of the results of bacteriological examination of sputum (and other specimens) more difficult. Nonetheless, this investigation shows that there is still a high probability of isolating Str. pneumoniae or $H$. influenzae from sputum of both medical and surgical patients with radiological evidence of pneumonia, provided they have not been given previous antibiotic therapy. In these circumstances the therapeutic course is fairly clear and few would be prepared to withhold therapy because in some cases the finding of these organisms may only reflect colonization of the upper respiratory tract without any causal relation to the pneumonia.

It is also known that antimicrobial therapy, often directed at infections in other anatomical sites, can rapidly ablate sensitive pathogens such as Str. pneumoniae and $H$. influenzae (Petersdorf et al., 1957). In this series there was a failure to isolate potential pathogens in a third of medical patients with evidence of consolidation who had been given previous therapy, compared with $12 \%$ of similar patients who had not had therapy. The figures for surgical patients were $43 \%$ and $8 \%$ respectively. In these circumstances it is likely that in some patients the pneumonia is already being adequately treated though it is often impossible to make this judgment in the individual case. A reasonable course is to continue the existing therapy with close observation of the patient's progress, including serial bacteriological investigations of sputum.

When a coliform is isolated from sputum of a patient with evidence of pneumonic consolidation the course of action is even less clear. In our medical patients with radiologically confirmed pneumonia coliforms were isolated from the sputum of $56 \%$ of those who had received previous antimicrobial therapy but from only $6 \%$ of those who had not. The corresponding figures for medical patients without pneumonic consolidation were $21 \%$ and $1 \%$ respectively, and a similar pattern was seen in corresponding surgical groups. Furthermore, of the 81 coliforms isolated from patients in all groups who had received previous therapy 76 were resistant to the agents already employed. This is consistent with previous reports that prophylactic antimicrobial therapy predisposes to the emergence of resistant coliforms in the respiratory tract (Lipman et al., 1946; Stratford et al., 1968; Johanson et al., 1969). In many patients these organisms colonize the respiratory tract without obvious associated disease. In certain (undefined) circumstances colonization may progress to an invasive bronchitis or pneumonitis. In other patients the presence of coliforms in sputum and the development of pneumonia are, presumably, dissociated events.

Unfortunately with current routine techniques it is often impossible to distinguish between these alternatives and define rational antimicrobial therapy for the individual patient with coliforms in the sputum. Consequently, the decision to treat can only be based on serial clinical, radiological, and bacteriological assessments with a bias in favour of therapy if in doubt. In this respect clearing of the chest radiograph after physiotherapy is often reassuring, particularly when a decision has been made not to treat a debilitated patient with large numbers of coliforms in the sputum. Unfortunately this manoeuvre does not exclude the possibility of bronchitis alone without pneumonia (Pines et al., 1970). Clearly, the isolation of the same organism from both sputum and blood can identify invasive disease .with high probability (Austrian and Gold, 1964; Johnson et al., 1968). Unfortunately experience suggests that this combination is less common with coliform infections than is the case with pneumococcal pneumonia (Austrian and Gold, 1964). Whether transtracheal needle aspiration, which avoids pharyngeal and oral contamination, will help resolve these difficulties remains to be seen.
Regarding the effect of the hospital environment on the acquisition and growth of coliform flora in the respiratory tract, studies in an intensive care unit (Johanson et al., 1972) have suggested that most patients who acquire these organisms do so within five days of admission. In this study most patients had been in hospital for more than three days before sputum was submitted for examination, but coliforms were isolated from only four of the 334 patients who had not received previous antimicrobial therapy. It therefore seems that in our hospital the general ward environment alone is not an important factor.

Another possible cause of the acquisition of coliforms is underlying disease (Stratford et al., 1968; Johanson et al., 1969). Unfortunately we were unable to dissociate this factor from the effects of antimicrobial therapy and, quite apant from ethical considerations, it is difficult to see how a definitive trial could be designed. It is theoretically possible that those patients most likely to acquire coliform flora as a result of their primary disease are also most likely to be given antibiotics. One exception to that is, of course, the well recognized finding of Pseudomonas aeruginosa in the sputum of patients with a tracheostomy.

Finally, the results suggest the possibility that, apart from changing both the rate and pattern of isolation of potential pathogens in sputum previous antimicrobial therapy may actually increase the absolute risk of secondary pneumonia in hospital patients. Thus in patients developing a productive cough, previous therapy was associated with an increase in the incidence of pneumonia from $8 \%$ to $18 \%$ in medical patients and from $21 \%$ to $35 \%$ in postoperative patients. In order to investigate a causal relation, however, the patients would have to be allocated to treatment and non-treatment groups before the development of evidence of chest infection.

In view of the importance of the repercussions of previous therapy and the widespread use of prophylactic antibiotics these relations clearly need further study. At the very least previous therapy is associated with an increased incidence of resistant coliforms in sputum (and elsewhere). This along with the ablation of organisms such as the pneumococcus and $\boldsymbol{H}$. influenzae makes the interpretation of bacteriological findings more difficult and sometimes impossible. Furthermore, antimicrobial agents account for $15 \%$ of the adverse effects of drugs which occur in $15 \%$ of hospital patients (Philp, 1972). There is also the considerable cost factor already described (Philp, 1972). If in addition to these factors it can be shown that previous therapy also increases the absolute risk of secondary pneumonia in hospital patients it will become necessary to re-examine the balance between the benefits and hazards of prophylaxis. Clearly there might be no overall gain in some circumstances from reducing the risk of wound infection with a sensitive organism (if it is reduced) if the risk of a resistant respiratory or urinary infection is increased. This aspect has been largely ignored even in the better clinical trials of surgical prophylaxis. It is not impossible, if the total pioture were to be examined in this way, that current antimicrobial usage would be seen to have reached a point of inversion where, as a result of widespread usage, potential hazards have come to equal established benefits.

We should like to acknowledge helpful criticism from Professor R. E. O. Williams and the co-operation of all the physicians, surgeons, and radiologists at St. Mary's Hospital Medical School for allowing us to study patients under their care.

\section{References}

Austrian, R., and Gold, J. (1964). Annals of Internal Medicine, 60, 759 Cowan, S. T., and Steel, K. J. (1965). Manual for the Identification of Medical Bacteria. London, Cambridge University Press.

Medical Bacteria. London, Cambridge University Press.
Elmes, P. C., Knox, K., and Fletcher, C. M. (1953). Lancet, 2, 903.

Johanson, W. G., Pierce, A. K., and Sanford, J. P. (1969). New England Fournal of Medicine, 281, 1137. 
Johanson, W. G., Pierce, A. K., Sanford, J. P., and Thomas, G. D. (1972). Annals of Internal Medicine, 77, 701.

Johnson, W. D., Kaye, D., and Hook, E. W. (1968). American Review of Respiratory Diseases, $97,1112$.

Lipman, M. O., Coss, J. A., and Boots, R. H. (1946). Fournal of Bacteriology, $51,594$.

Long, D. A. (1947). British Medical fournal, 2, 819.

Louria, D. B., and Kaminski, T. (1962). American Review of Respiratory Diseases, 85, 649 .

McCurdy, R. S., and Neter, E. (1952). Pediatrics, 9, 572.

Meads, M., Rowe, W. P., and Haslam, N. M. (1951). Archives of Internal Medicine, 87, 533.
Ory, E. M., Harris, H. W., Meads, M., Wilcox, C., and Finland, M., (1946). fournal of Laboratory and Clinical Medicine, 31, 409.

Petersdorf, R. G., Curtin, J. A., Hoeprich, P. D., Peeler, R. N., and Bennett, I. L. (1957). New England fournal of Medicine, 257, 1001.

Philp, J. R. (1972). In Clinical Concepts in Infectious Diseases ed. L. E. Cluff and J. E. Johnson, p. 326. Baltimore, Williams and Wilkins.

Pines, A., Raafat, H., Siddiqui, G. M., and Greenfield, J. S. B. (1970) British Medical fournal, $1,663$.

Price, D. J. E., and Sleigh, J. D. (1970). Lancet, 2, 1213.

Stratford, B., Gallus, A. S., Mathiesson, A. M., and Dixson, S. (1968) Lancet, $\mathbf{1}, 68$.

Tillotson, J. R., and Finland, M. (1969). Fournal of Infectious Diseases, 119,

\title{
Radioisotopic Bone Scintigraphy with the Gamma Camera in the Investigation of Prostatic Cancer
}

\author{
R. J. SHEARER, A. R. CONSTABLE, M. GIRLING, W. F. HENDRY, J. D. FERGUSSON
}

British Medical fournal, 1974, 2, 362-365

\section{Summary}

Experience with $x$-rays, strontium-87m scintigraphy, and technetium-99m polyphosphate scintigraphy in the identification of bone metastases in 201 patients with prostatic cancer is reviewed. About $40 \%$ of the patients had demonstrable metastases in bone at the time of first presentation.

Comparative studies of $247 \mathrm{x}$-ray and $87 \mathrm{mSr}$ surveys indicated that $x$-rays failed to detect metastases in $10 \%$

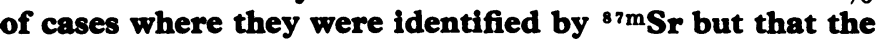
isotopic survey similarly failed to detect radiologically evident deposits in $7 \%$ of cases.

Similar studies comparing '9mTc polyphosphate surveys with $x$-ray scans showed that $x$-rays missed isotopically detected metastases in $12 \%$ of cases, but in only one survey out of 67 did the isotope miss radiologically evident deposits. In a series of 32 patients investigated by both isotopic techniques $"$ 'm Tc polyphosphate did not fail to detect any metastases and identified deposits in one patient in whom they were missed by ${ }^{87 m}$ Sr scintigraphy. About $15 \%$ of both $x$-ray and $87 \mathrm{mSr}$ surveys gave equivocal results, but only $3 \%$ ( 2 out of 67 ) of $9 m$ Tc polyphosphate surveys were equivocal.

We concluded that $\because \mathrm{m}$ Tc polyphosphate bone scintigraphy with the gamma camera was the most reliable of the techniques used for the identification of bone metastases in patients with carcinoma of the prostate. The results of scintigraphy with $87 \mathrm{~m}$ Sr suggested that serial surveys may provide early evidence of hormone resistance in prostatic cancer.

\section{Introduction}

Early and accurate recognition of bone metastases in patients with carcinoma of the prostate is an important part of the

Institute of Urology and St. Peter's Group of Hospitals, London WC2H 8JE

R. J. SHEARER, F.R.C.S., Research Fellow

A. R. CONSTABLE, M.SC., A.nNST.P., Senior Lecturer in Medical Physics A. R. CRN M. GIRLING, B.SC., Research Assistant
W. F. HENDRY, CH.M., F.R.C.S., Senior Lecturer and Honorary Consultant
Surgeon

J. D. FERGUSSON, M.D., F.R.C.s., Consultant Surgeon evaluation of the disease both at the time of initial presentation and during its subsequent course. Extensive change is needed in the texture of bone before metastases become radiologically visible and several reports have emphasized that radioisotopic bone scintigraphy can identify secondary deposits earlier than $x$-rays (Kontturi and Kiviniitty, 1971; Roy et al., 1971; Robinson and Constable, 1973). The principal nucleides used have been fluorine-18, strontium-85, or strontium-87m, but it is recognized that each isotope has drawbacks (O'Mara et al., 1972). Since the introduction of technetium-99m labelled polyphosphate (Subramanian and McAfee, 1971) there has been widespread acceptance of this compound, (Lavender et al., 1972; Redman and Turley, 1973) and clinical comparison of it with other isotopes is needed to evaluate its usefulness and accuracy in the investigation of prostatic carcinoma.

Between 1970 and December 1972 patients attending the prostatic carcinoma unit of the Institute of Urology were investigated by radiological skeletal surveys and by $87 \mathrm{mSr}$ bone scintigraphy. Between January and June $1973^{\circ} \mathrm{om}$ Tc polyphosphate scintigraphy was used as well, and in June 1973 $87 \mathrm{mSr}$ was discontinued. We here present our experience in the use of these various techniques in the recognition of bone secondary deposits.

\section{Patients and Methods}

All patients in this study attended a special unit for the investigation of prostatic cancer. In all cases the diagnosis was established by histological or cystological examination of a prostatic biopsy. A total of 201 patients were investigated by 305 radio-

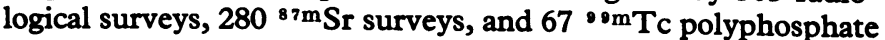
surveys. Radiological skeletal surveys were done by means of $x$-ray examinations of the chest, pelvis, lumbar and dorsal spines, skull (lateral view), femora, and humeri.

Bone scintigraphy was carried out with a Nuclear Enterprises Mk III gamma camera within a few days of the skeletal survey using either ${ }^{87 \mathrm{mSr}}$ or ${ }^{9} \mathrm{om}$ Tc polyphosphate (Manufactured by Diagnostic Isotopes Ltd. in kit form and supplied by Duphar Petten, Holland). In those cases where both agents were used the ${ }^{87 \mathrm{~m}} \mathrm{Sr}$ generally preceded the ${ }^{\circ 0 \mathrm{~m}} \mathrm{Tc}$ by five days.

The scintigraphic procedure was similar for both agents and the doses given were $1.5-2.0 \mathrm{mCi}{ }^{87} \mathrm{mSr}$ and $8-10 \mathrm{mCi}{ }^{9} 9 \mathrm{mTc}$ polyphosphate. The radiation dose to the patient was mainly to the skeleton in both investigations and totalled about 600 mrads for the combined study. The other critical organ was the kidney where the radiation dose can be at least as high as that to bone in the presence of good kidney function and outflow tract obstruction. The doses were given to the patient between 10 a.m. 